\title{
Efektivitas Edukasi Kesehatan Gigi dengan Metode Kombinasi terhadap Tingkat Kebersihan Mulut pada Anak Tunanetra
}

\author{
Miranda L. Kindangen, Damajanty H. C. Pangemanan, Christy N. Mintjelungan
}

\author{
Program Studi Pendidikan Dokter Gigi Fakultas Kedokteran Universitas Sam Ratulangi, \\ Manado, Indonesia \\ Email:miralvnia@gmail.com
}

\begin{abstract}
Dental health education (DHE) is important to improve the community oral health. Visually impaired children who have limited vision require appropriate methods according to the acceptance of them by maximizing the provision of education through the senses other than sight in carrying out treatment and prevention efforts. This study was aimed to obtain the effectiveness of DHE using a combination method in visually impaired children. This was a literature review study using the Google Scholar database, PubMed/ National Library of Medicine (NCBI), and Springer Link. After data selection based on inclusion and exclusion criteria, a critical appraisal was carried out. There were 10 literatures (six literatures of randomized controlled trial studies and four literatures of nonrandomized controlled trial/quasi experimental studies). The results showed that on average, the oral hygiene index score was lower after the intervention compared to before the DHE intervention using a combination method (braille, audio, and tactile). Moreover, the intervention decreased significantly the plaque index score and increased the number of visually impaired children who had good oral hygiene categories. In conclusion, DHE for visually impaired children using a combination method is effective in improving oral hygiene.
\end{abstract}

Keywords: dental health education (DHE); combination method; oral hygiene; visually impaired children

\begin{abstract}
Abstrak: Edukasi kesehatan gigi penting untuk meningkatkan kesehatan gigi dan mulut masyarakat. Anak tunanetra memiliki keterbatasan penglihatan sehingga memerlukan metode yang tepat dan sesuai penerimaan anak tunanetra dengan memaksimalkan pemberian edukasi melalui indra selain penglihatan dalam melakukan upaya perawatan dan pencegahan. Penelitian ini bertujuan untuk mengetahui efektivitas edukasi kesehatan gigi dengan menggunakan metode kombinasi pada anak tunanetra. Jenis penelitian ialah suatu literature review dengan menggunakan pencarian database Google Scholar, PubMed/National Library of Medicine (NCBI), dan Springer Link. Setelah melalui seleksi data berdasarkan kriteria inklusi dan eksklusi, dilakukan critical appraisal, kemudian didapatkan 10 literatur yang terdiri dari enam literatur dengan jenis studi randomized controlled trial dan empat literatur dengan jenis studi nonrandomized controlled trial/quasi experimental. Hasil penelitian mendapatkan bahwa umumnya hasil studi menunjukkan skor indeks kebersihan mulut lebih rendah sesudah intervensi dibandingkan dengan sebelum intervensi edukasi kesehatan gigi menggunakan metode kombinasi (braille, audio, dan taktil). Selain itu, secara bermakna intervensi menurunkan skor indeks plak dan meningkatkan jumlah anak tunanetra yang memiliki kategori kebersihan mulut yang baik. Simpulan penelitian ini ialah edukasi kesehatan gigi untuk anak tunanetra dengan metode kombinasi efektif meningkatkan kebersihan mulut.
\end{abstract}

Kata kunci: edukasi kesehatan gigi; metode kombinasi; kebersihan mulut; anak tunanetra

\section{PENDAHULUAN}

Edukasi kesehatan gigi adalah proses penyampaian informasi tentang kesehatan gigi dan mulut untuk meningkatkan pengetahuan secara keseluruhan dan membantu menumbuhkan kesadaran masyarakat akan 
pentingnya kebersihan mulut kemudian menanamkan kebiasaan pemeliharaan kesehatan gigi dan mulut. ${ }^{1}$ Edukasi kesehatan gigi diberikan tidak hanya pada anak normal namun juga kepada anak berkebutuhan khusus seperti anak tunanetra.

Anak tunanetra merupakan salah satu kategori dari anak berkebutuhan khusus dengan keterbatasan dalam penglihatan baik sebagian (low vision) maupun keseluruhan (buta total). ${ }^{2}$ Keterbatasan tersebut menjadi salah satu hambatan penyandang tunanetra untuk memperoleh pengetahuan kesehatan gigi dan mulut, dimana hal ini penting dalam membentuk sikap dan tindakan dalam menjaga kebersihan mulut anak tunanetra. ${ }^{3}$

Status kesehatan gigi dan mulut anak tunentra diketahui lebih buruk dibandingkan dengan individu penglihatan normal. ${ }^{4}$ Penelitian Marimbun et $\mathrm{al}^{2}$ menunjukkan bahwa $41,9 \%$ anak tunanetra dengan tingkat pengetahuan kesehatan gigi dan mulut yang baik dan sebanyak $58,1 \%$ dengan tingkat pengetahuan yang kurang. Data hasil pemeriksaan status karies gigi anak tunanetra yang diukur dengan menggunakan DMF-T menunjukkan 19,4\% memiliki status karies rendah dan $80,6 \%$ memiliki status karies tinggi. ${ }^{2}$ Data penelitian Marimbun et $\mathrm{al}^{2}$ menunjukkan adanya hubungan bermakna antara pengetahuan kesehatan gigi dan mulut dengan kesehatan gigi dan mulut pada anak berkebutuhan khusus tunanetra serta memberikan gambaran tingkat kesehatan gigi dan mulut yang belum mencapai kategori baik. $^{2}$ Pendekatan khusus kepada anak tunanetra dengan metode yang tepat dan sesuai penerimaan anak tunanetra diperlukan dalam melakukan upaya perawatan dan pencegahan. $^{5}$

Peningkatan kebersihan mulut pada anak tunanetra dapat dilakukan dengan cara memaksimalkan pemberian edukasi melalui indra yang lain selain indra penglihatan. Anak tunanetra memiliki kepekaan indra pendengaran dan perabaan yang lebih baik dibandingkan dengan anak normal. ${ }^{6}$ Macam-macam metode edukasi khusus yang dapat diberikan kepada anak-anak tunanetra antara lain audio yang menggunakan indrra pendengaran dan taktil yang menggunakan indra peraba seperti huruf braille, gambar timbul, dan model peraga 3 dimensi. ${ }^{7}$ Setiap metode memiliki kelemahan dan kelebihannya sehingga penggabungan dua atau lebih metode diharapkan dapat meningkatkan efektivitas penerimaan pengetahuan kesehatan gigi dan mulut dan membantu meningkatkan status kesehatan gigi dan mulut anak berkebutuhan khusus tunanetra menjadi lebih baik.

Berdasarkan latar belakang yang dipaparkan maka penulis tertarik untuk melakukan studi pustaka yang membahas dan menelaah berbagai informasi ilmiah terkait dengan efektivitas edukasi kesehatan gigi dengan metode kombinasi terhadap tingkat kebersihan mulut pada anak tunanetra.

\section{METODE PENELITIAN}

Penelitian ini merupakan penelitian kualitatif berbentuk literature review yang dilakukan pada bulan April-Juni 2021. Data sekunder berupa hasil penelitian, artikel atau jurnal ilmiah nasional maupun internasional, maupun buku teks dengan tema dan batasan tahun terbit 2015-2021 digunakan dalam penelitian ini. Pencarian data menggunakan Google Scholar, PubMed/National Library of Medicine (NCBI), dan Springer Link dengan kata kunci yakni Edukasi Kesehatan Gigi Mulut dan Anak Tunanetra baik dalam Bahasa Indonesia maupun Bahasa Inggris.

\section{HASIL PENELITIAN}

Literatur diseleksi berdasarkan kriteria inklusi dan eksklusi sehingga diperoleh 10 literatur dengan jenis studi randomized controlled trial dan empat literatur dengan jenis studi nonrandomized controlled trial/quasi experimental $(\mathrm{n}=10)$. Dilakukan uji kelayakan menggunakan The Joanna Briggs Institute (JBI) Critical Appraisal.

Tabel 1 memperlihatkan hasil utama literatur yang digunakan dalam penelitian ini yang memuat nama peneliti, tahun penelitian, judul, desain studi dan analisis, serta rangkuman hasil.

Keseluruhan literatur yang digunakan berasal dari negara India dengan total subjek penelitian sebanyak 1.067 anak yang terdiri 
dari laki-laki dan perempuan rentang usia 5 tahun hingga 18 tahun. Pengukuran indeks kebersihan mulut subjek penelitian sebelum intervensi (pre-intervention) dan sesudah intervensi (post-intervention) menggunakan instrumen penelitian yakni indeks plak Loe dan Silness digunakan pada tujuh literatur, indeks plak Quigley-Hein modifikasi digunakan pada dua literatur, dan indeks Patient Hygiene Performance (PHP) digunakan pada satu literatur yang tersisa.

Tahapan intervensi terdiri dari tahap 1 yaitu dilakukan pemeriksaan dan penilaian skor kebersihan mulut sebelum intervensi (baseline). Baseline merujuk pada informasi keadaan sebelum intervensi. Anak-anak diberikan intervensi edukasi kesehatan gigi dan mulut pada tahap 2 berdasarkan pembagian media (audio, braille, dan taktil) masingmasing kelompok uji. Reinforcement atau penguatan diberikan setelah intervensi awal (baseline) kecuali pada penelitian Ganapathi et $\mathrm{al}^{8}$ dan Sardana et $\mathrm{al}^{13}$ tidak disebutkan. Tahap 3 menilai kembali skor kebersihan mulut setelah intervensi.

Tabel 1. Hasil utama literatur yang digunakan dalam penelitian literature review

\begin{tabular}{|c|c|c|c|}
\hline $\begin{array}{l}\text { Peneliti dan } \\
\text { Tahun }\end{array}$ & Judul & $\begin{array}{c}\text { Design Study, Sampel, Variabel, } \\
\text { Instrumen, Analisis }\end{array}$ & Rangkuman Hasil \\
\hline $\begin{array}{l}\text { Ganapathi et } \\
\text { al, } 2015^{8}\end{array}$ & $\begin{array}{l}\text { Effectiveness of va- } \\
\text { rious sensory input } \\
\text { methods in dental } \\
\text { health education } \\
\begin{array}{l}\text { among } \\
\text { children }\end{array}\end{array}$ & $\begin{array}{l}\text { Design: randomized controlled trial } \\
\text { Sampel: } 200 \text { anak-anak berumur 8-14 tahun } \\
\text { (laki-laki dan perempuan) yang kooperatif di } \\
\text { India, yang buta total tanpa penyakit bawaan } \\
\text { atau sistemik, kecacatan, dan menggunakan } \\
\text { perangkat orthodontik } \\
\text { Variabel: Kelompok } 1 \text { (audio), kelompok } 2 \\
\text { (braille), kelompok } 3 \text { (model gigi), } \\
\text { kelompok } 4 \text { (multi-sensori; kombinasi audio, } \\
\text { braille, taktil), dan kelompok kontrol } \\
\text { Instrumen: Indeks plak modifikasi Quigley- } \\
\text { Hein (pre- dan post-) } \\
\text { Analisis: Paired T-test dan ANOVA test }\end{array}$ & $\begin{array}{l}\text { Skor plak secara statistik } \\
\text { signifikan di semua kelom- } \\
\text { pok studi jika disbanding- } \\
\text { kan dengan skor awal. }\end{array}$ \\
\hline $\begin{array}{l}\text { Chowdary et } \\
\text { al, } 2016^{9}\end{array}$ & $\begin{array}{l}\text { Impact of verbal, } \\
\text { braille text, and } \\
\text { tactile oral hygiene } \\
\text { awareness instruct- } \\
\text { tions on oral health } \\
\text { status of visually } \\
\text { impaired children }\end{array}$ & $\begin{array}{l}\text { Design: nonrandomized controlled trial } \\
\text { (Kuasi Eksperimental) } \\
\text { Sampel: } 120 \text { anak-anak berumur 6-16 tahun } \\
\text { (laki-laki dan perempuan) di India yang buta } \\
\text { total tanpa masalah mental, penyakit siste- } \\
\text { mik, kecacatan, sedang dalam penggunaan } \\
\text { bahan kimia untuk kontrol plak, dan } \\
\text { pengobatan yang dapat berpengaruh pada } \\
\text { jaringan gingiva } \\
\text { Variabel: Kelompok } 1 \text { (verbal dan taktil), } \\
\text { kelompok } 2 \text { (verbal dan braille), dan } \\
\text { kelompok } 3 \text { (verbal, braille, taktil) } \\
\text { Instrumen: Indeks plak Loe dan Silness (pre- } \\
\text { dan post-) } \\
\text { Analisis: ANOVA test }\end{array}$ & $\begin{array}{l}\text { Anak-anak di semua } \\
\text { kelompok menunjukkan } \\
\text { penurunan skor plak } \\
\text { dengan persentase } \\
\text { penurunan skor plak } \\
\text { tertinggi pada kelompok } 3 \\
(70,6 \%) \text {. }\end{array}$ \\
\hline $\begin{array}{l}\text { Gautam et } \\
\text { al, } 2017^{10}\end{array}$ & $\begin{array}{l}\text { Effect of oral health } \\
\text { education by audio } \\
\text { aids, braille \& } \\
\text { tactile models on } \\
\text { the oral health } \\
\text { status of visually } \\
\text { impaired children } \\
\text { of Bhopal City }\end{array}$ & $\begin{array}{l}\text { Design: randomized controlled trial } \\
\text { Instrumen: Indeks Patient Hygiene } \\
\text { Performance (PHP) (pre-dan post-) } \\
\text { Sampel: } 60 \text { anak-anak berumur 5-18 tahun di } \\
\text { kota Bhopal, India dengan tanpa penyakit } \\
\text { sistemik, riwayat penggunaan antibiotik } \\
\text { sistemik atau perawatan topikal flour; tidak } \\
\text { menggunakan suplemen probiotik atau } \\
\text { suplemen oral hygiene, tidak dalam pera- } \\
\text { watan gigi, konsumsi permen karet xylitol, }\end{array}$ & $\begin{array}{l}\text { Penurunan skor rata-rata } \\
\text { plak (yaitu peningkatan } \\
\text { perbedaan rata-rata skor } \\
\text { PHP) pada semua interval } \\
\text { waktu dalam kelompok } \\
\text { individu yang signifikan } \\
\text { secara statistik disbanding- } \\
\text { kan dengan awal. }\end{array}$ \\
\hline
\end{tabular}


Deshpande et al, $2017^{11}$

Das et al, $2018^{12}$

Sardana et al, $2019^{13}$

Tiwari et al, $2019^{14}$
Effectiveness of braille and audiotactile performance technique for improving oral hygiene status of visually impaired adolescents

Effectiveness of a
novel oral health
education tech-
nique in mainte-
nance of gingival
health and plaque
removal efficacy
among institutiona-
lized visually im-
paired children of
Bhubaneswar City
Bhubaneswar City dan kondisi medis yang parah

Variabel: Kelompok A (audio dan braille), kelompok B (audio dan taktil model), dan kelompok C (audio, braille, dan model taktil) Analisis: ANOVA test

\section{Design: randomized controlled trial}

Sampel: 60 anak-anak remaja laki-laki buta total berumur 12-16 tahun yang kooperatif di India dengan tanpa disabilitas atau sindrom.

Variabel: Kelompok 1 (braille), kelompok 2 (audio secara verbal dijelaskan dan taktil), dan kelompok 3 (kombinasi braille dan audio tactile performance (ATP))

Instrumen: Indeks plak Loe dan Silness (predan post-)

Analisis: ANOVA test dan U-test

Design: randomized controlled trial

Sampel: 60 anak-anak (38 laki-laki dan 22 perempuan) buta total berumur 10-15 tahun yang kooperatif di kota Bhubaneswar, India dengan tanpa penyakit sistemik, disabilitas, sindrom; tidak menggunakan suplemen oral hygiene seperti obat kumur, tidak memiliki riwayat terbaru perawatan gigi, antibiotik sistemik, atau perawatan topikal fluor 3 bulan sebelumnya atau pada saat pengambilan data awal peneltiian; tidak menggunakan protesa/ gigi tiruan

Variabel: Kelompok kontrol yang diberikan edukasi dengan media braille dan audio, dan kelompok uji yang diberikan edukasi dengan media audio-tactile performance (ATP)

Instrumen: Indeks plak Quigley-Hein modifikasi Turesky

Analisis: T-test, Chi square test, dan ANOVA test

Effect of specially designed oral health preventive programme on oral health of visually impaired children: use of audio and tactile aids

Design: randomized controlled trial

Sampel: 148 anak-anak (100 laki-laki dan 48 perempuan) berumur 10-17 tahun di India yang buta total dengan tanpa penyakit sistemik.

Variabel: Kelompok 1 (braille dan model plastik) dan kelompok 2 (audio dan JAWS (Job Access with Speech (sebuah pembaca layar) merupakan peranti lunak yang berguna untuk membantu penderita tunanetra menggunakan komputer)

Instrumen: Indeks plak Loe dan Silness (predan post-)

Analisis: Independent sample dan paired Ttest, Chi square test

Effectiveness of different oral health education interventions in visually impaired school children $(73,3 \%$ laki-laki $=66$ orang dan $26,7 \%$
Design: non-randomized controlled trial (kuasi eksperimental)

Sampel: 90 anak-anak berumur 12-15 tahun perempuan $=24$ orang) di India yang buta sebagian dan total dengan tanpa gangguan medis, kecacatan intelektual, sedang dalam penggunaan bahan kimia untuk kontrol plak,
Rata-rata skor indeks plak setelah intervensi meningkat di kelompok 1 sedangkan skor plak rata-rata menurun di kelompok 2 dan 3. Penurunan skor yang paling banyak terdapat pada kelompok 3 .

Pada kelompok kontrol, penurunan plak lebih besar pada interval 30 hari bila dibandingkan dengan interval awal dan 90 hari. Dalam kelompok uji (ATP), penurunan skor gingiva yang lebih besar diamati pada interval 90 hari bila dibandingkan dengan interval awal dan 30 hari.

Kelompok 1 memiliki skor rata-rata plak menurun pada 3 bulan, dengan penurunan lebih lanjut pada 6 bulan pasca implementasi. Skor rata-rata plak di kelompok 2 menurun setelah 3 bulan selanjutnya pada 6 bulan pasca pelaksanaan program pendidikan.

Kelompok 3 menunjukkan persentase tertinggi penurunan skor plak (55\%) bila dibandingkan dengan kelompok 1 dan kelompok 2. 


\begin{tabular}{|c|c|c|c|}
\hline & & $\begin{array}{l}\text { dan sedang dalam pengobatan yang dapat } \\
\text { berpengaruh pada jaringan gingiva } \\
\text { Variabel: Kelompok } 1 \text { (audio-tactile perfor- } \\
\text { mance (ATP)), kelompok } 2 \text { (braille), dan } \\
\text { kelompok } 3 \text { (audio-tactile performance } \\
\text { (ATP) dan braille) } \\
\text { Instrumen: Indeks plak Loe dan Silness (pre- } \\
\text { dan post) } \\
\text { Analisis: ANOVA test }\end{array}$ & \\
\hline $\begin{array}{l}\text { Gautam et } \\
\text { al, } 2020^{15}\end{array}$ & $\begin{array}{l}\text { New vision for } \\
\text { improving oral } \\
\text { hygiene status of } \\
\text { visually impaired } \\
\text { students aged from } \\
9 \text { to } 17 \text { years }\end{array}$ & $\begin{array}{l}\text { Design: randomized controlled trial } \\
\text { Sampel: } 180 \text { anak-anak buta total berumur 9- } \\
17 \text { tahun di India yang kooperatif dengan } \\
\text { tanpa adanya gangguan indra lainnya } \\
\text { Variabel: Kelompok } 1 \text { (braille), kelompok } 2 \\
\text { (audio-tactile performance (ATP)) dan } \\
\text { kelompok } 3 \text { (braille dan audio-tactile } \\
\text { performance (BATP)) } \\
\text { Instrumen: Indeks plak Loe dan Silness (pre- } \\
\text { dan post-) } \\
\text { Analisis: Paired } t \text {-test dan ANOVA test }\end{array}$ & $\begin{array}{l}\text { Ada perbedaan yang sangat } \\
\text { bermakna terlihat untuk } \\
\text { perbandingan antar kelom- } \\
\text { pok pasca dengan rata-rata } \\
\text { skor indeks plak paling } \\
\text { sedikit di kelompok } 3 \text {. }\end{array}$ \\
\hline $\begin{array}{l}\text { Debnath et } \\
\text { al, } 2017^{16}\end{array}$ & $\begin{array}{l}\text { New vision for im- } \\
\text { proving the oral } \\
\text { healthy education } \\
\text { of visually impaired } \\
\text { children }\end{array}$ & $\begin{array}{l}\text { Design: non-randomized control trial } \\
\text { Sampel: } 40 \text { anak-anak buta total dan buta } \\
\text { sebagian berumur } 8-18 \text { tahun di India dengan } \\
\text { tanpa adanya keterbelakangan mental, cacat } \\
\text { mental, cacat ortopedi, dan cerebral palsy } \\
\text { Variabel: Kelompok dengan intervensi } \\
\text { metode kombinasi (audio, braille, dan taktil) } \\
\text { Instrumen: Indeks plak Loe dan Silness (pre- } \\
\text { dan post-) } \\
\text { Analisis: Chi square-test }\end{array}$ & $\begin{array}{l}\text { Ada perubahan yang } \\
\text { bermakna pada skor plak } \\
\text { dengan } 80 \% \text { anak-anak } \\
\text { memiliki skor yang cukup } \\
\text { pada sebelum intervensi } \\
\text { menjadi } 30 \% \text { pada setelah } \\
\text { intervensi. }\end{array}$ \\
\hline $\begin{array}{l}\text { Aggarwal et } \\
\text { al, } 2019^{17}\end{array}$ & $\begin{array}{l}\text { Assessment of oral } \\
\text { health educational } \\
\text { program on oral } \\
\text { health status of } \\
\text { visually impaired } \\
\text { children in New } \\
\text { Delhi }\end{array}$ & $\begin{array}{l}\text { Design: } \text { non-randomized control trial } \\
\text { Sampel: } 120 \text { anak-anak (namun pada akhir } \\
\text { bulan kesembilan tersisa } 109 \text { anak, karena } \\
\text { absen pada pemeriksaan berikutnya) berumur } \\
\text { 5-15 tahun di India } \\
\text { Variabel: Kelompok dengan intervensi meto- } \\
\text { de kombinasi (audio, braille, dan taktil) } \\
\text { Instrumen: Indeks plak Loe dan Silness (pre- } \\
\text { dan post-) } \\
\text { Analisis: T-test }\end{array}$ & $\begin{array}{l}\text { Ada penurunan yang ber- } \\
\text { makna secara statistik pada } \\
\text { indeks plak skor pada akhir } \\
\text { bulan ke sembilan. }\end{array}$ \\
\hline
\end{tabular}

Data pemeriksaan, penilaian, dan selisih skor indeks kebersihan mulut sebelum dan sesudah intervensi edukasi kesehatan gigi dan mulut dengan metode kombinasi pada anak dikumpulkan dan disajikan dalam Tabel 2. Berbeda pada penelitian Debnath et $\mathrm{al}^{13}$ yang memberikan informasi distribusi jumlah anak berdasarkan kategori indeks kebersihan mulut (Tabel 3).

\section{BAHASAN}

Edukasi kesehatan gigi dan mulut merupakan pendekatan yang diterima secara luas dalam pencegahan masalah kesehatan gigi dan mulut. Program ini membawa perilaku baru untuk memperkuat dan mempertahankan gaya hidup sehat yang akan memromosikan dan meningkatkan kesehatan individu. ${ }^{14}$ Tunanetra adalah istilah untuk orang yang mengalami gangguan fungsi indera penglihatan sehingga tunanetra berusaha memaksimalkan fungsi indera perabaan, penciuman, pendengaran dan lain sebagainya. ${ }^{18}$ Anak tunanetra merupakan kelompok besar anak berkebutuhan khusus yang memerlukan pengembangan pendekatan khusus dalam edukasi dan pemeliharaan kesehatan gigi dan mulut. ${ }^{19}$ 
Tabel 2. Distribusi rerata skor indeks kebersihan mulut setiap literatur

\begin{tabular}{cccccc}
\hline & & \multicolumn{2}{c}{ Rerata } & & \\
No & Peneliti & Skor Indeks Kebersihan Mulut & Selisih rerata \\
Skor Indeks & Niai p \\
\cline { 3 - 4 } & & $\begin{array}{c}\text { Sebelum } \\
\text { Intervensi }\end{array}$ & $\begin{array}{c}\text { Sesudah } \\
\text { Intervensi }\end{array}$ & \\
\hline 1 & Ganapathi et al $^{8}$ & $2,63 \pm 0,76$ & $1,80 \pm 0,45$ & 0,83 & $<0,001$ \\
2 & Chowdary eta al $^{9}$ & $1,09 \pm 0,19$ & $0,32 \pm 0,17$ & 0,69 & $0,00^{* *}$ \\
3 & Gautam et al $^{10}$ & $0,65 \pm 0,49$ & $0,15 \pm 0,37$ & 0,50 & 0,004 \\
4 & Deshpande et al $^{11}$ & $30,23^{* * *}$ & $18,73^{* * *}$ & 11,5 & $0,001^{* *}$ \\
5 & Das et al $^{12}$ & $3,53 \pm 1,32$ & $1,47 \pm 1,32$ & 2,06 & 0,148 \\
6 & Sardana et al $^{13}$ & $1,24 \pm 0,47$ & $1,10 \pm 0,17$ & 0,14 & $<0,05$ \\
7 & Tiwari et al $^{14}$ & $1,74 \pm 0,29$ & $0,79 \pm 0,14$ & 0,95 & $<0,001$ \\
8 & Gautam et al $^{15}$ & $1,84 \pm 0,39$ & $0,80 \pm 0,27$ & 1,04 & $0,000^{* *}$ \\
9 & Aggarwal T $^{\text {et al }}$ & $1,21 \pm 0,74$ & $1,02 \pm 0,70$ & 0,19 & 0,0001 \\
\hline
\end{tabular}

Keterangan: *Statistically significant; **Highly significant; *** Mean rank

Tabel 3. Distribusi jumlah anak masing-masing kelompok berdasarkan kategori skor indeks plak Silness dan Loe pada penelitian Debnath et al ${ }^{16}$

\begin{tabular}{|c|c|c|c|c|c|c|}
\hline \multirow{2}{*}{$\begin{array}{c}\text { Kelompok/ } \\
\text { Media }\end{array}$} & \multirow{2}{*}{$\begin{array}{c}\text { Interval } \\
\text { Waktu }\end{array}$} & \multirow[b]{2}{*}{$\mathbf{n}$} & \multicolumn{3}{|c|}{$\begin{array}{c}\text { Indeks plak } \\
\text { (Silness dan Loe) }\end{array}$} & \multirow{2}{*}{ Nilai $p$} \\
\hline & & & $\begin{array}{l}\text { Baik } \\
(0-0,9)\end{array}$ & $\begin{array}{c}\text { Sedang } \\
(1.0-1.9)\end{array}$ & $\begin{array}{l}\text { Buruk } \\
(2.0-3.0)\end{array}$ & \\
\hline $\begin{array}{c}\text { Kelompok } \\
\text { audio + braille }\end{array}$ & Baseline & $\begin{array}{c}40 \\
(100 \%)\end{array}$ & $\begin{array}{c}2 \\
(5.0 \%)\end{array}$ & $\begin{array}{c}32 \\
(80.0 \%)\end{array}$ & $\begin{array}{c}6 \\
(15.0 \%)\end{array}$ & $<0.001$ \\
\hline+ taktil & 6 bulan & $\begin{array}{c}40 \\
(100 \%)\end{array}$ & $\begin{array}{c}27 \\
(67,5 \%)\end{array}$ & $\begin{array}{c}12 \\
(30,0 \%)\end{array}$ & $\begin{array}{c}1 \\
(2,5 \%)\end{array}$ & \\
\hline
\end{tabular}

Keterangan: *Statistically significant; **Highly significant

Jumlah anak tunanetra sebanyak 1.067 anak dalam studi pustaka ini, terdiri dari laki-laki dan perempuan dengan rentang usia mulai dari 5 tahun hingga 18 tahun. Rentang usia ini berdasarkan UndangUndang Republik Indonesia Nomor 23 Tahun 2002 tentang Perlindungan Anak, pasal 1 Ayat 1, yang berbunyi anak adalah seseorang yang belum berusia 18 (delapan belas) tahun, termasuk anak yang masih dalam kandungan dan menurut definisi World Health Organization, dimana batasan usia anak adalah sejak anak di dalam kandungan sampai usia 19 tahun. $^{20}$

Penelitian pada 10 literatur dalam studi pustaka ini menilai perubahan yang terjadi berdasarkan keadaan sesudah dan sebelum diberikan intervensi kepada masing-masing kelompok uji menggunakan metode kombinasi (braille, audio, dan taktil). ${ }^{8-17}$
Pengambilan dan penilaian kebersihan mulut anak tunanetra sebelum dan sesudah dilakukan intervensi edukasi kesehatan gigi dan mulut menggunakan indeks plak Loe dan Silness, indeks plak Quigley-Hein modifikasi, dan indeks Patient Hygiene Performance $(P H P))^{21}$ Ketiga indeks ini memiliki kesamaan dalam menilai ketebalan maupun luas plak dan debris sebagai indikasi kebersihan mulut. Hal yang membedakan ketiga indeks tersebut terletak pada area plak yang dinilai, dimana indeks plak Loe dan Silness menilai empat area yakni distal, fasial atau bukal, mesial, dan lingual pada enam gigi yang mewakili; indeks plak Quigley-Hein modifikasi hanya permukaan fasial (sepertiga gingiva) dari gigi anterior; serta indeks Patient Hygiene Performance (PHP) di permukaan fasial gigi untuk gigi insisivus dan gigi molar 
rahang atas sedangkan permukaan lingual untuk gigi molar rahang bawah dengan jumlah enam gigi yang mewakili. $^{21}$

Berdasarkan rangkuman hasil penelitian 10 literatur yang digunakan, diketahui bahwa setelah pemberian edukasi kesehatan gigi kepada anak tunanetra dengan metode kombinasi (braille, audio, dan taktil) menunjukkan adanya penurunan skor indeks kebersihan mulut yang signifikan. Metode kombinasi berupa BATP (braille, audio, and tactile performance) membantu memaksimalkan indra anak tunanetra yang tersisa. Edukasi melalui braille dapat memberikan pemahaman kepada anak tunanetra ketika mereka membaca. Audio yang berisikan penjelasan dengan musik, dapat meningkatkan ketertarikan dan membuat suasana menjadi menyenangkan. Meraba model taktil seperti model gigi, dapat menghasilkan pemahaman bentuk dan lokasi yang lebih akurat bagi anak tunanetra. Pendampingan orang lain seperti guru atau pengasuh dalam mengarahkan praktik menyikat gigi atau edukasi lainnya, membantu anak tunanetra mengingat Langkah-langkah suatu prosedur dalam menjaga kesehatan gigi dan mulut.

Konsep pengulangan dan penguatan instruksi kebersihan mulut menunjukkan efek yang signifikan, positif, jangka pendek, dan jangka panjang. ${ }^{22}$ Untuk itu, delapan dari 10 literatur yang digunakan menyebutkan aktivitas reinforcement atau penguatan yang dilakukan kepada anak-anak tunanetra dengan beragam interval waktu tergantung lama interval waktu penelitian tiap literatur. Pengaruh aktivitas ini terhadap efektifitas edukasi kesehatan gigi sejalan dengan penelitian Haleem et $\mathrm{al}^{23}$ yang menyatakan bahwa pengulangan (repetition) dan penguatan (reinforcement) memainkan peran kunci dalam keberhasilan program DHE berbasis sekolah tidak masalah apakah itu dipimpin oleh dokter gigi, guru atau pemimpin sebaya.

Perbedaan penurunan skor indeks masing-masing penelitian dalam kesepuluh literatur dapat dikarenakan perbedaan dalam jumlah subjek setiap penelitian, skor indeks kebersihan mulut pada baseline setiap anak tunanetra yang beragam, rentang waktu follow-up/pengambilan data akhir setelah intervensi yang beragam, dan rentang kategori usia anak yang dapat memengaruhi tingkat pengetahuan dan pemahaman edukasi yang diberikan.

\section{SIMPULAN}

Gabungan media edukasi kesehatan gigi dan mulut untuk anak tunanetra yaitu braille, audio, dan taktil menjadi metode kombinasi efektif membantu anak-anak tunanetra meningkatkan kebersihan mulut.

\section{Konflik Kepentingan}

Penulis menyatakan tidak terdapat konflik kepentingan dalam studi ini.

\section{DAFTAR PUSTAKA}

1. Ghaffari M, Rakhshanderou S, Ramezankhani A, Noroozi M, Armoon B. Oral health education and promotion programmes: meta-analysis of 17-year intervention. Int J Dent Hyg. 2018;16(1):59-67.

2. Marimbun BE, Mintjelungan CN, Pangemanan DHC. Hubungan tingkat pengetahuan tentang kesehatan gigi dan mulut dengan status karies gigi pada penyandang tunanetra. e-GiGi. 2016;4(2):1-5.

3. Alamsyah RM, Natassa SE. Difference in effectiveness of dental health education between braille and audio method towards the knowledge and oral health (OHIS) score among the blind children in Karya Murni Foundation, Tunanetra Foundation and Binjai Special Needs Foundation. Atl Press. 2018;8.

4. Octiara E, Salmiah S, Amalia Z, Luthfiani. Sekolah Luar Biasa Taman Pendidikan Islam Medan. J USU - Abdimas Talent 3. 2018;3(1):81-9.

5. Wright GZ, Kupietzky A. Behavior Management in Dentistry for Children (2nd ed) Vol. 36. UK: Wiley Blackwell, 2014; p. 1-248.

6. Ulya E, Budiono I, Mardiana. Efektivitas Media booklet braille dalam meningkatkan pengetahuan gizi pada anak tunanetra. Unnes J Public Health. 2014;3(4):48-55.

7. Dewi RK, Alphianti LT. Perbedaan tingkat pengetahuan kesehatan gigi dan mulut anak tunanetra usia 7-11 tahun antara 
penyuluhan metode leaflet braille dan metode audio (Kajian di SLB-A Yaketunis Yogyakarta). J UMY Yogyakarta. 2017;1-7.

8. Ganapathi AK, Namineni S, Vaaka PH, K V, Das R, Devi M, et al. Effectiveness of Various sensory input methods in dental health health education among blind children- a comparative study. J Clin Diagnostic Res. 2015;9(10):75-8.

9. Chowdary PB, Uloopi K, Vinay C, Rao VV, Rayala C. Impact of verbal, braille text, and tactile oral hygiene awareness instructions on oral health status of visually impaired children. J Indian Soc Pedod Prev Dent. 2016;34(1):437.

10. Gautam A, Bhambal A, Moghe S. Effect of oral health education by audio aids, Braille \& tactile models on the oral health status of visually impaired children of Bhopal city. J Oral Biol Craniofacial Res. 2017;8(3):168-70.

11. Deshpande S, Rajpurohit L, Kokka VV. Effectiveness of braille and audiotactile performance technique for improving oral hygiene status of visually impaired adolescents. J Indian Soc Periodontol. 2017;21(1):27-31.

12. Das D, Suresan V, Jnaneswar A, Pathi J, Subramaniam GB. Effectiveness of a novel oral health education technique in maintenance of gingival health and plaque removal efficacy among institutionalized visually impaired children of Bhubaneswar city: A randomized controlled trial. Spec Care Dent. 2018;39(2):1-10.

13. Sardana D, Goyal A, Gauba K, Kapur A, Manchanda S. Effect of specially designed oral health preventive programme on oral health of visually impaired children: use of audio and tactile aids. Int Dent $\mathrm{J}$ [Internet]. 2019;69(2):98-106. Available from: https://doi.org/10.1111/idj.12436

14. Tiwari BS, Ankola A V., Jalihal S, Patil P, Sankeshwari RM, Kashyap BR. Effectiveness of different oral health education interventions in visually impaired school children. Spec Care Dent. 2019;39(2):97-107.

15. Gautam K, Ali AR, Agrawal D, Choudhary A, Shekhawat A, Jain RL. New vision for improving oral hygiene status of visually impaired students aged from 9 to 17 years. J Fam Med Prim Care. 2020;9(10):5303-8.

16. Debnath A, Srivastava BK, Shetty P, Eshwar $\mathrm{S}$. New vision for improving the oral health education of visually impaired children. J Clin Diagnostic Res. 2017; 11(7):29-32.

17. Aggarwal T, Goswami M, Dhillon JK. Assessment of oral health educational program on oral health status of visually impaired children in New Delhi. Spec Care Dent. 2019;1-7.

18. Sabilillah MF, Taftazani RZ, Sopianah Y, Fatmasari D. Pengaruh Dental braille education (dbe) terhadap oral hygiene pada anak tunanetra. J Kesehat Gigi. 2016;03(2):7-13.

19. Doichinova L, Gateva N, Hristov K. Oral hygiene education of special needs children. Part 2: visually impaired children. Biotechnol Biotechnol Equip. 2019;33(1):821-6.

20. Info DATIN KEMENKES RI: Kondisi Pencapaian Program Kesehatan Anak Indonesia Vol. 53. Jakarta: Pusat Data dan Informasi Kementerian Kesehatan Republik Indonesia, 2014.

21. Marya C. A Textbook of Public Health Dentistry. New Delhi: Jaypee Brothers Medical Publishers, 2011.

22. Khurana C, Tandon S, Chand S, Chinmaya BR. Effectiveness of oral health education program using braille text in a group of visually impaired childrenbefore and after comparison trial. $\mathrm{J}$ Educ Health Promot. 2019;8(50):1-6.

23. Haleem A, Khan MK, Sufia S, Chaudhry S, Siddiqui MI, Khan AA. The role of repetition and reinforcement in school-based oral health education-a cluster randomized controlled trial. BioMed Cent Public Heal. 2016;16(2):1-12. 